\title{
Expression of Laminin $\gamma 2$ in Extrahepatic Cholangiocarcinoma Tissues and its Influence on Tumor Invasion and Metastasis
}

\author{
Yong Li, Da-Jiang Li, Jian Chen, Wei Liu, Jian-Wei Li, Peng Jiang, Xin Zhao, \\ Fei Guo, Xiao-Wu Li, Shu-Guang Wang*
}

\begin{abstract}
Objective: To explore the expression of laminin $\gamma 2$ in extrahepatic cholangiocarcinoma (EHCC) tissues and its influence on tumor invasion and metastasis. Materials and Methods: Paraffin embedding samples of cancer, para-cancer, lymph node metastatic and hepatic metastatic tissues from 79 patients undergoing EHCC resection were collected. Expression of laminin $\gamma 2$ was detected by immunohistochemistry and its relationship with clinical pathological characteristics and the prognosis of EHCC patients were analyzed. Results: Laminin 2 showed negative staining in para-cancer tissues, but demonstrated a 51.9\% (41/79) positive expression rate in extracellular matrix (ECM) or cytoplasm of EHCC tissues. In lymph node metastatic and distant metastatic nidi, expression of laminin $\gamma 2$ was significantly higher than in the primary nidi $\left(\chi^{2}=7.4173, P=0.0065 ; \chi^{2}=4.0077, P=0.0453\right)$. The expression was in obvious association with lymph node metastasis $(P<0.01)$, but had no relevance with age, gender, tumor location, tumor stage, differentiation and distant metastasis in ECM $(P>0.05)$, whereas it was in marked connection with lymph node and distant metastasis $(P<0.05$ or $P<0.01)$, but had no relationship with age, gender, tumor location, tumor stage and differentiation in cytoplasm $(P>0.05)$. However, the median survival time and median recurrent period of patients with positive expression of laminin $\gamma 2$ in both cytoplasm and ECM of tumor cells, only in ECM and only in cytoplasm, were evidently lower than with negative expression of laminin $\gamma 2$ in RCM and cytoplasm $(P<0.05$ or $P<0.01)$. Further Cox regression analysis showed that the positive expression of laminin $\gamma 2$ and the tumor differentiation were independent risk factors influencing the prognosis of EHCC patients. Conclusions: Abnormal expression of laminin $\gamma 2$ may be closely associated with invasion and metastasis of tumor cells, and thus a potential molecular marker for prognosis of EHCC patients.
\end{abstract}

Keywords: Laminin $\gamma 2$ - extrahepatic cholangiocarcinoma - lymph node metastasis - distant metastasis

Asian Pac J Cancer Prev, 16 (5), 2099-2102

\section{Introduction}

Extrahepatic cholangiocarcinoma (EHCC), which is a kind of malignant tumor derived from the extrahepatic biliary epithelial cells with high malignant severity and recessive attack, is generally treated with surgeries (Pattanathien et al., 2013; Huai et al., 2014). However, the recurrence is extremely high due to the invasion and metastasis in the early stage of EHCC, which severely threatens patients' prognosis (Yang et al., 2014).

Laminin332, as a macromolecular glycoprotein, is widely distributed in epithelial cells. It plays an important biological function in the metastasis, proliferation, growth and differentiation of cells by combing with receptors to mediate the adhesion between cells and basilar membrane (Kamoshida, et al., 2014). During the developmental process of tumors, the interaction of tumor cells and basilar membrane is the basis of the invasion and metastasis of tumors. Studies demonstrated that the abnormal distribution of Laminin 332 might be in close association with the malignant transformation of epithelial cells as well as the invasion and metastasis of tumors (Kariya et al., 2012; Kim et al., 2012). Laminin $\gamma 2$ chain, as a special part of Laminin332, is secreted in monomeric form, which has no expression in normal intrahepatic biliary epithelial cells and the basilar membrane of biliary epithelial tissues, but expresses highly in the cytoplasm of cholangiocarcinoma cells and extracellular matrix (ECM) (Liu et al., 2014).

To further definite the effect of Laminin $\gamma 2$ in the development and progression of EHCC, this research analyzed the expression of Laminin $\gamma 2$ and its relationship with clinical pathological characteristics and prognosis of EHCC patients, hoping to provide a theoretical basis for the predication of the invasion and metastasis of EHCC. 


\section{Materials and Methods}

\section{General data}

Paraffin embedding samples of cancer tissues, para-cancer tissues, lymph nose metastatic tissues and hepatic metastatic tissues from 79 patients undergoing EHCC resection in Sounthwest Hospital, Third Military Medical University from January, 2010 to October, 2014 were collected. All patients were diagnosed as RHCC by histopathological and (or) cytological examination. Clinical data were complete, and no patient received neoadjuvant chemotherapy (NACT) or radiotherapy (NART) before operation. All surgical edges were negative. There were 48 males and 31 females, aged $34 \sim 72$ years, with average age being $(56.91 \pm 8.75)$ years; tumor locations: hepatic polar (64 cases) and distant ones (15 cases); differentiation severity: high differentiation (23 cases), moderate differentiation (46 cases) and low differentiation (10 cases); TNM stages: T1 (11 cases), T2 (30 cases), T3 (23 cases) and T4 (15 cases); lymph node metastasis: yes (31 cases) and no (48 cases); and distant metastasis: yes (17 cases) and no (62 cases)

\section{Methods}

The expression of Laminin $\gamma 2$ in the cancer tissues, para-cancer tissues, lymph nose metastatic tissues and hepatic metastatic tissues of EHCC was detected by immunohistochemical method. The detailed processes were as follows: the paraffin embedding samples were collected and cut into $4 \mu \mathrm{m}$ slices, followed by routine dimethylbenzene deparaffinage, gradient alcohol hydration, sealing of endogenous peroxidase (EPOD) by $3 \%$ hydrogen peroxide solution and antibody repair with $10 \mathrm{mmol} / \mathrm{L} \mathrm{pH} 6.0$ citric acid buffer solution. After antibody repair, primary antibodies (mice anti-human Laminin $\gamma 2$ monoclonal antibodies were purchased from American Novus company) were added and put into wet boxes to be incubated at $4^{\circ} \mathrm{Covernight,} \mathrm{after} \mathrm{which} \mathrm{they}$ were brought out to be re-warmed for $30 \mathrm{~min}$ at room temperature, soaked for 3 times by phosphate buffer solution (PBS), $5 \mathrm{~min} /$ time. Horseradish peroxidase (HRP)-marked secondary antibody working solution (goat anti-mice HRP-marked secondary antibodies were bought from Beijing Zhongshan Jinqiao Biotechnology Co., Ltd.) $30 \mu \mathrm{L}$ was added, incubated in $37^{\circ} \mathrm{C}$ dry box for $30 \mathrm{~min}$, soaked by PBS for 3 times ( $5 \mathrm{~min} / \mathrm{time}$ ), colored with diaminobenzidine (DAB) (DAB staining kits were obtained from Beijing Zhongshan Jinqiao Biotechnology Co., Ltd.), washed by flow water, restained by hematoxylin, dehydrated, naturally dried and sealed with neutral resins. The known positive slices served as positive control and PBS as negative control instead of primary antibodies.

\section{Observational indexes}

The positive expression rates of Laminin $\gamma 2$ in cancer tissues, para-cancer tissues, lymph nose metastatic tissues and hepatic metastatic tissues were observed and their relationships with clinical pathological characteristics and prognosis were analyzed.

\section{Evaluation criteria}

Two physicians in Department of Pathology, without being informed of the patients' clinical data, were invited to observe and diagnose all slices independently. The positive cells were defined as the brown granules in ECM and cytoplasm. Ten high-fold fields $(\times 400)$ were randomly selected from each slice to calculate the total number of tumor cells and the positive cell count. The slice was considered to be positive if the positive expression of cells $>5 \%$, or be negative.

\section{Statistical data analysis}

SAS 9.3 software package was applied for all data statistics. The measurement data were expressed by mean \pm standard deviation $(\mathrm{X} \pm \mathrm{S})$ and analyzed with independent-sample t test. Enumeration data were expressed by percentage (\%), and comparison between two samples were analyzed by four-table $\chi^{2}$ test while that between multiple samples by line-table $\chi^{2}$ test. KaplanMeier survival curve was adopted for the analysis of survival time and Log-rank test was conducted. Cox risk regression model was applied for the multivariate analysis of factors influencing patients' prognosis. Two-sided test was used for all statistical analysis with $\alpha=0.05$ as the inspection level.

\section{Results}

Expression of Laminin $\gamma 2$ in primary nidi, metastatic nidi and para-cancer tissues

In EHCC tissues, Laminin $\gamma 2$ expressed in ECM and cytoplasm, with positive rate being $51.90 \%$ (41/79), in which $39.24 \%$ (31/79) expressed in ECM, 32.91\% (26/79) in cytoplasm and 20.25\% (16/79) in both ECM and cytoplasm. However, the expression of Laminin $\gamma 2$ in para-cancer tissues showed negative staining.

In tissues of lymph node metastatic and distant metastatic nidi, Laminin $\gamma 2$ expressed in cytoplasm with positive rate being $61.29 \%(19 / 31)$ and $58.82 \%(10 / 17)$, respectively, and there were significant differences when

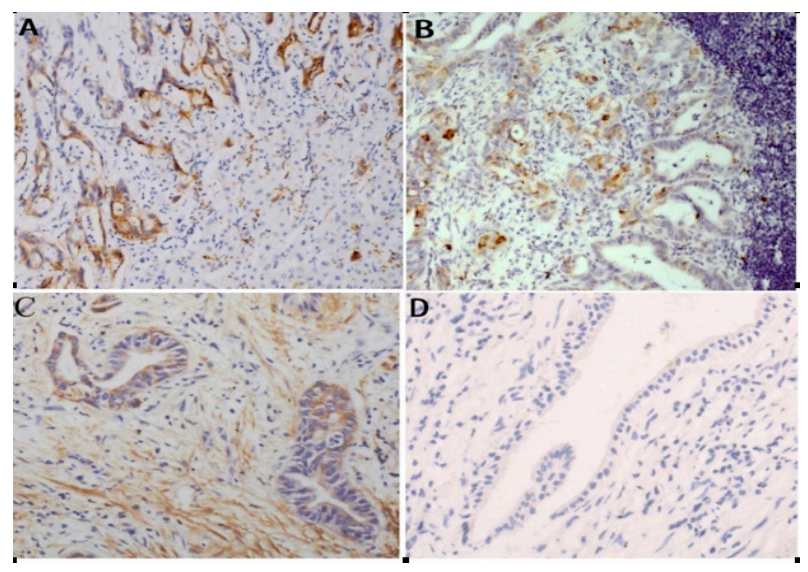

Figure 1. Expression of Laminin $\gamma 2$ in Primary Nidi, Metastatic Nidi and Para-cancer Tissues

Note: A: Expression of Laminin $\gamma 2$ in distant metastatic nidi; B: Expression of Laminin $\gamma 2$ in lymph node metastatic nidi; C: Expression of Laminin $\gamma 2$ in primary nidi; D: Expression of Laminin $\gamma 2$ in para-cancer tissues. 
Table 1. Relevance Between Expression of Laminin 22 and Clinical Pathological Characteristics of EHCC Patients

\begin{tabular}{|c|c|c|c|c|c|c|c|c|}
\hline \multirow[t]{2}{*}{$\begin{array}{l}\text { Pathological } \\
\text { characteristics }\end{array}$} & \multicolumn{2}{|c|}{$\begin{array}{c}\text { Expression of Laminin } \gamma 2 \\
\text { in ECM }\end{array}$} & \multirow[t]{2}{*}{$\mathrm{T}$ or $\chi^{2}$} & \multirow[t]{2}{*}{$P$} & \multicolumn{2}{|c|}{$\begin{array}{c}\text { Expression of Laminin } \gamma 2 \\
\text { in cytoplasm }\end{array}$} & \multirow[t]{2}{*}{$\mathrm{T}$ or $\chi^{2}$} & \multirow[t]{2}{*}{$P$} \\
\hline & Positive [n (\%)] & Negative $[\mathrm{n}(\%)]$ & & & Positive [n (\%) & Negative [n (\%)] & & \\
\hline Ages & $59.13 \pm 10.05$ & $57.61 \pm 9.85$ & 0.66 & 0.5084 & $58.19 \pm 9.08$ & $57.71 \pm 8.74$ & 0.23 & 0.8150 \\
\hline \multicolumn{9}{|l|}{ Genders } \\
\hline Male & $17(54.84)$ & $31(64.58)$ & \multirow[t]{2}{*}{0.7502} & \multirow[t]{2}{*}{0.3864} & $14(53.85)$ & $34(64.15)$ & \multirow[t]{2}{*}{0.7769} & \multirow[t]{2}{*}{0.3781} \\
\hline Female & $14(45.16)$ & $17(35.42)$ & & & $12(46.15)$ & $19(35.85)$ & & \\
\hline \multicolumn{9}{|l|}{ Tumor locations } \\
\hline Hepatic portal & $24(77.42)$ & $40(83.33)$ & \multirow[t]{2}{*}{0.4283} & \multirow[t]{2}{*}{0.5128} & $18(69.23)$ & $46(86.79)$ & \multirow[t]{2}{*}{3.4973} & \multirow[t]{2}{*}{0.0615} \\
\hline Distance & $7(22.58)$ & $8(16.67)$ & & & $8(30.77)$ & $7(13.21)$ & & \\
\hline \multicolumn{9}{|l|}{ Tumor stages } \\
\hline $\mathrm{T} 1$ & $1(3.23)$ & $10(20.83)$ & \multirow{4}{*}{5.8183} & \multirow{4}{*}{0.1208} & $2(7.69)$ & $9(16.98)$ & \multirow[t]{4}{*}{7.3423} & \multirow[t]{4}{*}{0.0618} \\
\hline $\mathrm{T} 2$ & $12(38.71)$ & $18(37.50)$ & & & $6(23.08)$ & $24(45.28)$ & & \\
\hline $\mathrm{T} 3$ & $12(38.71)$ & $11(22.92)$ & & & $10(38.46)$ & $13(24.53)$ & & \\
\hline $\mathrm{T} 4$ & $6(19.35)$ & $9(18.75)$ & & & $8(30.77)$ & $7(13.21)$ & & \\
\hline \multicolumn{9}{|c|}{ Differentiation degree } \\
\hline High differentiation & $7(22.58)$ & $16(33.33)$ & \multirow[t]{3}{*}{1.0969} & \multirow[t]{3}{*}{0.5778} & $4(15.38)$ & $19(35.85)$ & \multirow[t]{3}{*}{4.1726} & \multirow[t]{3}{*}{0.1241} \\
\hline $\begin{array}{l}\text { Moderate } \\
\text { differentiation }\end{array}$ & $20(64.52)$ & $26(54.17)$ & & & $17(65.38)$ & $29(54.72)$ & & \\
\hline $\begin{array}{l}\text { Low } \\
\text { differentiation }\end{array}$ & $4(12.90)$ & $6(12.50)$ & & & $5(19.23)$ & $5(9.43)$ & & \\
\hline \multicolumn{9}{|c|}{ Lymph node metastasis } \\
\hline Yes & $18(58.06)$ & $13(27.08)$ & \multirow[t]{2}{*}{7.5827} & \multirow[t]{2}{*}{0.0059} & $15(57.69)$ & $16(30.19)$ & \multirow[t]{2}{*}{5.5342} & \multirow[t]{2}{*}{0.0186} \\
\hline No & $13(41.94)$ & $35(72.92)$ & & & $11(42.31)$ & $37(69.81)$ & & \\
\hline \multicolumn{9}{|l|}{ Distant metastasis } \\
\hline Yes & $10(32.26)$ & $7(14.58)$ & 3.4841 & 0.0620 & $11(42.31)$ & $6(11.32)$ & 9.9173 & 0.0016 \\
\hline No & $21(67.74)$ & $41(85.42)$ & & & $15(57.69)$ & $47(88.68)$ & & \\
\hline
\end{tabular}

Table 2. Cox Multivariate Analysis of Factors Influencing Prognosis of EHCC Patients

\begin{tabular}{|c|c|c|c|c|c|}
\hline \multirow[t]{2}{*}{ Factors } & \multirow[t]{2}{*}{ df } & \multirow[t]{2}{*}{ Sig. } & \multirow[t]{2}{*}{$\operatorname{Exp}(B)$} & \multicolumn{2}{|c|}{$95.0 \%$ confidence interval } \\
\hline & & & & Lower limit & Upper limit \\
\hline Ages & 1 & 0.968 & 0.998 & 0.967 & 1.047 \\
\hline Gender & 1 & 0.829 & 1.053 & 0.596 & 1.712 \\
\hline $\begin{array}{l}\text { Tumor } \\
\text { location }\end{array}$ & 1 & 0.631 & 0.857 & 0.325 & 1.984 \\
\hline $\begin{array}{l}\text { Lymph node } \\
\text { metastasis }\end{array}$ & 1 & 0.306 & 0.636 & 0.365 & 1.102 \\
\hline $\begin{array}{l}\text { Distant } \\
\text { metastasis }\end{array}$ & 1 & 0.476 & 1.011 & 0.929 & 1.083 \\
\hline $\begin{array}{l}\text { Laminin } \gamma 2 \\
\text { expression }\end{array}$ & 1 & 0.003 & 2.196 & 1.179 & 4.197 \\
\hline $\begin{array}{l}\text { Differentiation } \\
\text { severity }\end{array}$ & 2 & 0.036 & & & \\
\hline $\begin{array}{l}\text { Differentiation } \\
\text { severity (1) }\end{array}$ & 1 & 0.046 & 2.537 & 1.264 & 6.089 \\
\hline $\begin{array}{l}\text { Differentiation } \\
\text { severity (2) }\end{array}$ & 1 & 0.025 & 3.855 & 1.716 & 7.997 \\
\hline Tumor stage & 3 & 0.197 & & & \\
\hline Tumor stage (1) & ) 1 & 0.133 & 0.887 & 0.434 & 1.721 \\
\hline Tumor stage (2) & ) 1 & 0.694 & 2.001 & 0.965 & 4.685 \\
\hline Tumor stage (3) & 1 & 0.241 & 1.563 & 0.787 & 3.166 \\
\hline
\end{tabular}

compared with positive expression of rate of Laminin $\gamma 2$ in primary cytoplasm $\left(\chi^{2}=7.4173, P=0.0065 ; \chi^{2}=4.0077\right.$, $P=0.0453$ ) (Figure 1).

Relevance between expression of Laminin 2 and the clinical pathological characteristics of EHCC patients

Of the 79 EHCC patients, Laminin $\gamma 2$ expression was in obvious association with lymph node metastasis $(P<0.01)$, but had no relevance with ages, genders, tumor locations, tumor stages, differentiation severity and distant metastasis in ECM $(P>0.05)$, whereas it was in marked connection with lymph node and distant metastasis in cytoplasm $(P<0.05$ or $P<0.01)$, but had no relationship with ages, genders, tumor locations, tumor stages and differentiation $(P>0.05)$ (Table 1$)$.

\section{Influence of Laminin 2 on prognosis of EHCC patients}

The median survival time (MST) of patients with positive expression of Laminin $\gamma 2$ in both cytoplasm and ECM of cancer cells, only in ECM and only in cytoplasm was 8.5, 9.0 and 8.7 months respectively, and the differences were significant when compared with that (22.0 months) of patients with negative expression in ECM and cytoplasm $(P=0.0018)$. The median recurrent period of patients with positive Laminin $\gamma 2$ expression in both cytoplasm and ECM of cancer cells, only in ECM and only in cytoplasm was 6.0, 7.0 and 4.0 months, and there were significant differences when compared with that (16.0 months) in patients with negative expression in ECM and cytoplasm $(P=0.0001)$.

To further exclude other influencing factors, Cox regression analysis (involving ages, genders, tumor locations, etc.) was performed and it showed that the positive expression of Laminin $\gamma 2$ and tumor differentiation severity were the independent risk factors influencing the prognosis of EHCC patients (Table 2).

\section{Discussion}

Laminin332, as one of the Laminin (LN) family, is the primary ingredient of basilar membrane, which mainly mediates the adhesion between epithelial cells and basilar membrane. A study indicated that Laminin332 did not express in normal mucous cells, but over-expressed in the 
cytoplasm of primary andeocarcinoma cells (Imura et al., 2012), whose expression increase was in close correlation with the metastasis and proliferation of multiple tumor cells (Kinoshita et al., 2012; Fukuchi et al., 2013). Laminin332 is composed of three chains termed by $\alpha 3, \beta 3$ and $\gamma 2$, in which Laminin $\gamma 2$, as the only polypeptide chain, is secreted in monomeric form. Some scholars believed that Laminin $\gamma 2$ could trigger the functional loss of endothelial barrier by extracting vascular endothelial cells and increasing vascular permeability so as to increase the metastasis of tumor cells and improve their invasive growth (Sato et al., 2014). The research results of Degen et al illustrated that during the process of tumor developing into invasive squamouscell carcinoma, the expression of Laminin $\gamma 2$ increased significantly (Degen et al., 2013). In this study, Laminin $\gamma 2$, which expressed abnormally high in cancer tissues, had no expression in para-cancer tissues, and the further analysis of the relevance between the expression of Laminin $\gamma 2$ and the clinical pathological characteristics demonstrated that the expression of Laminin $\gamma 2$ was significantly connected with lymph node metastasis and distant metastasis in cytoplasm, and with lymph node metastasis in ECM, suggesting that Laminin $\gamma 2$ expressed abnormally in cancer tissues, which was in obvious association with the invasion and metastasis of tumor cells.

The invasion and metastasis of tumors can directly influence the prognosis of patients and the over-expression of Laminin $\gamma 2$ may lead to poorer prognosis of tumor patients. It has been reported that in patients with bladder carcinoma, the expression of Laminin $\gamma 2$ is closely related with the tumor stages and differentiation severity, becoming an independent risk factor for the tumor progression (Kang et al., 2013); that in normal esophageal tissues, Laminin $\gamma 2$ expresses in basilar membrane, which shows high expression in the oncocyte cytoplasm of esophageal squamous cell carcinoma tissues, and the expression condition is in close correlation with the survival time of patients with esophageal carcinoma in phase II, and the higher the expression, the poorer the prognosis (Xue et al., 2011); that the survival time of patients with oral squamous cell carcinoma (OSCC) who are with positive expression of Laminin $\gamma 2$ is significantly shorter than in patients with negative expression, indicating that Laminin $\gamma 2$ may be a reliable predicative index for patients with OSCC (Gasparoni et al., 2007). This study, through Kaplan-Meier models, found that in EHCC patients, the survival time and recurrent period in patients with positive expression of Laminin $\gamma 2$ were evidently lower than in those with negative expression, and further Cox model analysis showed that the positive expression of Laminin $\gamma 2$ was an independent risk factor impacting the survival time and recurrence of EHCC patients, demonstrating that the positive expression of Laminin $\gamma 2$ was a potential molecular biological marker for the prognostic diagnosis of cancer patients.

To sum, the invasion and metastasis of tumors as well as postoperative recurrence can all affect EHCC patients' prognosis. The results of this study suggested that Laminin $\gamma 2$ could lead to the poor prognosis by participating the invasion and metastasis of tumor and influencing the tumor recurrence. However, the mechanism has not been deeply explored in this study, and how the Laminin $\gamma 2$ improves the invasion and metastasis of tumors and impacts the postoperative recurrence of EHCC patients still need to be further studied.

\section{References}

Degen M, Barron P, Natarajan E, et al (2013). RSK activation of translation factor eIF4B drives abnormal increases of laminin $\gamma 2$ and MYC protein during neoplastic progression to squamous cell carcinoma. PLoS One, 8, e78979.

Fukuchi O, Suko A, Matsuzaki H, et al (2013). Anti-laminin-332 mucous membrane pemphigoid with autoantibodies to $\alpha 3$, $\beta 3$ and $\gamma 2$ subunits of laminin-332 as well as to BP230 and periplakin associated with adenocarcinoma from an unknown primary site. J Dermatol, 40, 61-2.

Huai JP, Ding J, Ye XH, et al (2014). Inflammatory bowel disease and risk of cholangiocarcinoma: evidence from a metaanalysis of population-based studies. Asian Pac J Cancer Prev, 15, 3477-82.

Gasparoni A, Della Casa M, Milillo L, et al (2007). Prognostic value of differential expression of Laminin-5 gamma2 in oral squamous cell carcinomas: correlation with survival. Oncol Rep, 18, 793-800.

Imura J, Uchida Y, Nomoto K, et al (2012). Laminin-5 is a biomarker of invasiveness in cervical adenocarcinoma. Diagn Pathol, 7, 105.

Kariya Y, Sato H, Katou N, et al (2012). Polymerized laminin-332 matrix supports rapid and tight adhesion of keratinocytes, suppressing cell migration. PLoS One, 7, e35546.

Kim BG, Gao MQ, Choi YP, et al (2012). Invasive breast cancer induces laminin-332 upregulation and integrin $\beta 4$ neoexpression in myofibroblasts to confer an anoikis-resistant phenotype during tissue remodeling. Breast Cancer Res, 14, R88.

Kinoshita T, Hanazawa T, Nohata N, et al (2012). Tumor suppressive microRNA-218 inhibits cancer cell migration and invasion through targeting laminin-332 in head and neck squamous cell carcinoma. Oncotarget, 3, 1386-400.

Kang SG, Ha YR, Ko YH, et al (2013). Effect of laminin 332 on motility and invasion in bladder cancer. Kaohsiung $\mathrm{J} \mathrm{Med}$ Sci, 29, 422-9.

Kamoshida G, Ogawa T, Oyanagi J, et al (2014). Modulation of matrix metalloproteinase- 9 secretion from tumorassociated macrophage-like cells by proteolytically processed laminin-332 (laminin-5). Clin Exp Metastasis, 31, 285-91.

Liu W, Tian F, Jiang P, et al (2014). Aberrant expression of laminin $\gamma 2$ correlates with poor prognosis and promotes invasion in extrahepatic cholangiocarcinoma. J Surg Res, 186, 150-6.

Pattanathien P, Khuntikeo N, Promthet S, et al (2013). Survival rate of extrahepatic cholangiocarcinoma patients after surgical treatment in Thailand. Asian Pac J Cancer Prev, 14, 321-4.

Sato H, Oyanagi J, Komiya E, et al (2014). Amino-terminal fragments of laminin $\gamma 2$ chain retract vascular endothelial cells and increase vascular permeability. Cancer Sci, 105, 168-75.

Xue LY, Zou SM, Zheng S, et al (2011). Expressions of the $\gamma 2$ chain of laminin-5 and secreted protein acidic and rich in cysteine in esophageal squamous cell carcinoma and their relation to prognosis. Chin J Cancer, 30, 69-78.

Yang H, Zhou J, Wei X, et al (2014). Survival outcomes and progonostic factors of extrahepatic cholangiocarcinoma patients following surgical resection: Adjuvant therapy is a favorable prognostic factor. Mol Clin Oncol, 2, 1069-75. 